\title{
First report of alfalfa mosaic virus in Ligularia fischeri in Korea
}

\author{
Chung Youl Park ${ }^{1} \cdot$ Hyun-Geun Min ${ }^{1} \cdot$ Go Eun Shin ${ }^{1} \cdot$ Jonghee $\mathrm{Oh}^{1} \cdot$ Su-Heon Lee ${ }^{1,2}$
}

Published online: 12 March 2018

(C) The Author(s) 2018

Keywords Alfalfa mosaic virus $\cdot$ Ligularia fischeri

Ligularia fischeri (Family Asteraceae), a perennial vegetable plant, is commonly used as a food in Korea. In March 2015, two symptomatic samples of greenhouse-grown L. fischeri plants showing mosaic and malformation on their leaves and one symptomless sample were collected from Gangwon Province in South Korea. To identify the infecting virus, total RNA was extracted from the pooled symptomatic leaves using an RNA extraction kit (Intron Biotechnology, Seoul, Korea) and subjected to RNA sequencing. The raw data analysis of RNA sequencing $(50,830,462$ reads) performed according to Zhao et al. (2016) showed 12 viral contigs (102-2352 bp) of alfalfa mosaic virus (AMV), covering the RNA3 segment of AMV genome. One large contig (2352 bp) had 90\% sequence identity with AMV Manfredi isolate (KC881010). Based on the contigs, two primer sets AMV-MP-1F/1R (5'GTAATTCGTACTCTTCGTGAGT-3'/5'-GCATAGTT CTGAGAACGTTTAG-3') producing a 1140 bp amplicon and AMV-CP-1F/1R (5'-TGATCGGTAATGGGCCGTTT3'/5' -TTAATCCACCCAGTGGAGGT-3') producing a $780 \mathrm{bp}$ amplicon were newly designed and used to confirm the presence of AMV by reverse-transcription PCR (RT-PCR) and sequencing. The two symptomatic samples were positive for AMV, whereas the asymptomatic sample was negative by RT-PCR. The complete sequences of movement protein (MP)

Su-Heon Lee

suheon@knu.ac.kr

1 School of Applied Biosciences, Kyungpook National University, Daegu 41566, South Korea

2 Institute of Plant Medicine, Kyungpook National University, Daegu 41566, South Korea and coat protein $(\mathrm{CP})$ genes of Korean AMV isolate Gomchi infecting $L$. fischeri were deposited to GenBank (accession Nos. LC219342 and LC219343, respectively). A BLAST search revealed the highest nucleotide sequence identities of 95\% to KC881010 (MP sequence of AMV isolate Manfredi) and $99 \%$ to LN846978 (CP sequence of AMV isolate shark) for LC219342 and LC219343, respectively. Sap from one of the positive samples was mechanically inoculated onto Vigna sinensis and Chenopodium amaranticolor. Necrotic local lesions were observed 3 days post-inoculation (dpi), and mosaic and vein banding symptoms developed on the upper leaves of V. sinensis and C. amaranticolor 7-10 dpi, respectively. Presence of AMV in the inoculated plants was also confirmed by RT-PCR and direct sequencing. To our knowledge, this is the first report of an AMV infection of $L$. fischeri in Korea.

Acknowledgements This research was supported by a grant from the Animal and Plant Quarantine Agency (QIA), Ministry of Agriculture, Republic of Korea (Project Code No. Z-1542051-2013-15-01).

Open Access This article is distributed under the terms of the Creative Commons Attribution 4.0 International License (http:// creativecommons.org/licenses/by/4.0/), which permits unrestricted use, distribution, and reproduction in any medium, provided you give appropriate credit to the original author(s) and the source, provide a link to the Creative Commons license, and indicate if changes were made.

\section{Reference}

Zhao F, Lim S, Yoo RH, Igori D, Kim SM, Kwak DY, Kim SL, Lee $\mathrm{BC}$, Moon JS (2016) The complete genomic sequence of a tentative new polerovirus identified in barley in South Korea. Arch Virol 16:2047-2050 